CASE STUDY

\title{
Making a Place for Curricular \\ Transformation at the University of Technology Sydney
}

August 17, 2015

Nancy Fried Foster

Christine Mulhern

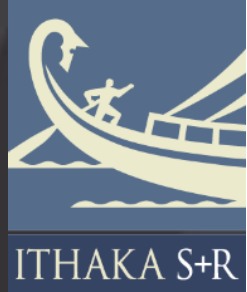




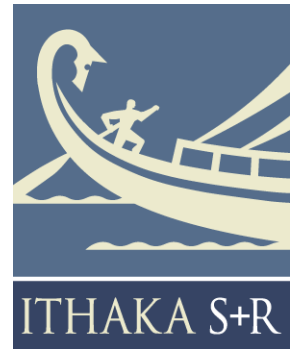

Ithaka $\mathrm{S}+\mathrm{R}$ is a strategic consulting and research service provided by ITHAKA, a not-for-profit organization dedicated to helping the academic community use digital technologies to preserve the scholarly record and to advance research and teaching in sustainable ways. Ithaka $\mathrm{S}+\mathrm{R}$ focuses on the transformation of scholarship and teaching in an online environment, with the goal of identifying the critical issues facing our community and acting as a catalyst for change. JSTOR, a research and learning platform, and Portico, a digital preservation service, are also part of ITHAKA.
Copyright 2015 ITHAKA. This work is licensed under a Creative Commons Attribution-NonCommercial 4.0 International License. To view a copy of the license, please see http://creativecommons.org/licenses/by-nc/4.0/.

ITHAKA is interested in disseminating this case study as widely as possible. Please contact us with any questions about using the case study: research@ithaka.org. 


\section{Introduction}

The University of Technology Sydney (UTS) is committed to research and learning in technology-based disciplines, such as engineering and information technology, and fields that rely heavily on technology, such as design, architecture and building. Located in the center of Sydney, Australia, the university aims to achieve world-class status through embedding of advanced technologies across the curriculum, strong academic performance in science, engineering and technology, orientation to industry and professions, and alignment with Australian economic and educational priorities. ${ }^{1}$

Over the past eight years, UTS has pursued a plan to expand and improve its facilities while transforming its pedagogical approach. It implemented a highly interactive, practice-based learning approach across the institution while undertaking construction of seven new technology-enhanced buildings to support overall growth and programmatic change. These bold moves, conceived and implemented nearly simultaneously and increasingly integrated into one overarching enterprise, are grand and risky. But, so far, they also constitute an extremely promising effort to turn UTS into a major player in Australian higher education while preparing its graduates to be capable, knowledgeable, and attractive to employers in Australia and beyond.

Once a dingy collection of buildings from which students fled when their lectures and tutorials were done for the day, the UTS campus is now buzzing with activity morning to night as students meet and work in several bright new buildings and cleverly renovated spaces. New and refreshed spaces are designed specifically to support student learning through group work, flipped classes, and other new approaches. At the same time, these spaces advance pedagogical changes by facilitating staff innovation in the classroom while making it harder to default to large-scale lectures. ${ }^{2}$

The progress that UTS has made in its twin initiatives can be traced back several years to a compelling vision, key decisions, and the expertise and will of individuals at every level of the organization. In the beginning, UTS leaders articulated a top-down vision of student learning based on research, enhanced by technology, and enabled by purposebuilt learning environments. Then they set about to create the conditions that would enable staff to make the vision a reality from the bottom up. The key initiative,

\footnotetext{
${ }^{1}$ For information on the university's strategic direction: http://www.uts.edu.au/about/university/uts-strategic-direction.

${ }^{2}$ Australian terms are used in this case study. In some cases they have a different meaning than the terms in American English. In particular, "staff" refers to faculty members, "courses" are degree programs, "subjects" are courses, faculties or faculty units are departments, and "schools" are university divisions (such as arts and sciences).
} 
Learning2014, began with a shift in the pedagogical model and some small-scale renovations. From these experiments grew the knowledge and the resolve to go big.

In April 2015 one of us (Foster) visited the University of Technology Sydney to talk with more than 20 leaders and administrators, academic and support staff, and students, to understand the origins of these initiatives and their purpose, challenges and how they have been addressed, developments thus far, and plans for the future. ${ }^{3}$ In this case study we describe the changes that have taken place at UTS, the inspiration behind them, how such large changes have been effectively implemented, and their overall impact on the university.

\section{Origins}

Although it can trace its history to the nineteenth century, UTS gained its current name and configuration in 1988, initially through incorporation of the former New South Wales Institute of Technology and, in 1990, by amalgamation of the Institute of Technical and Adult Teacher Education and the Kuring-gai College of Advanced Education. With more than 35,000 students, it is now one of Australia's largest universities. The university offers courses in business, communication, education, engineering, health, information technology, international studies, law, science, and design, architecture and building.

While UTS has traditionally focused on technology fields and practice-based learning, its current learning model and the vision driving the ongoing expansion of its facilities are new, dating back only about eight years. A turning point came in 2007, when the UTS Student Satisfaction Survey yielded mainly good results but indicated that learning spaces were both of "high importance" and "low performance," confirming what many had already casually observed.

\section{Working Groups}

UTS had recently been awarded federal "reward funds" for its high ranking in the Teaching and Learning Performance Fund, and university management decided to allocate a proportion of these funds to projects to improve learning. They organized their approach to the improvement of learning around four main areas: students, the curriculum, learning technologies, and learning spaces. Working groups of

\footnotetext{
${ }^{3}$ We thank Shirley Alexander for her gracious hospitality in hosting this visit, which included several walking tours of the UTS campus and participation in the opening of the new Faculty of Science and Graduate School of Health building. We also thank Anna Neo for coordination of the visit and scheduling of more than 20 interviews in a very short space of time.
} 
administrators and staff were organized for all four areas under the management of the university's Teaching and Learning Committee, with overall leadership by Professor Shirley Alexander. The efforts of the four working groups constituted a major initiative, Learning2014, which focused on construction and renovation of learning spaces and the development of new education practices by the academic staff.

\section{Students}

In short order, the students working group reviewed enrolment and demographic data and discovered that students were, in general, not financially well-off and that a large number were employed on a full- or part-time basis. Few students remained on campus for anything other than direct instruction, and the number of days students even came to campus at all had declined from five per week to just three.

\section{Curriculum}

The curriculum working group focused on developing a curriculum based on the UTS Model of Learning oriented to the preparation of students for the evolving demands of careers in technology fields. 4 They concluded that a shift in practice was needed in order to achieve the three cornerstones of the learning model:

» "An integrated exposure to professional practice through dynamic and multifaceted modes of practice-oriented education"

» "Professional practice situated in a global workplace, with international mobility and international and cultural engagement as centerpiece"

» "Learning that is research-inspired and integrated, providing academic rigor with cutting edge technology to equip graduates for life-long learning"

The group recommended broadening the range of practice-oriented and authentic learning approaches, including work-based learning, problem-based activities, simulations, and real and virtual field trips. They also encouraged an intentional focus on the development of graduate attributes such as collaboration and communication, and international and intercultural engagement. Students would engage in more active, creative, and inquiry-based work, reflect on their own learning, and prepare for a globally connected workplace.

UTS advanced the efforts of the curriculum working group by introducing annual learning and teaching grants to support curriculum change and innovation. Larger

${ }^{4}$ See "UTS Model of Learning." http://www.uts.edu.au/about/university/uts-strategic-direction. 
grants supported teams within the faculty units to redesign courses in line with the UTS model and begin to develop graduate attributes in the curriculum of key undergraduate courses. Smaller learning and teaching grants supported academic staff to engage in bottom-up curriculum innovation in their subjects. This funding simultaneously conferred practical and symbolic support for curricular change, both providing the wherewithal for the desired changes and signaling their importance to the institution.

\section{Learning Technologies}

The learning technologies group undertook the identification and implementation of digital tools that would support and enrich student learning and further improve the curriculum. The group focused on online platforms to enhance content and student engagement with instructors and peers. Its suggestions included a tool to document work-based learning and internships, software to assess graduate attributes, and an application to support self-assessments and peer review. As new technologies were introduced to support emerging educational practices, communities formed to provide technical and peer support to academic staff engaged in implementing changes in their subjects.

\section{Learning Spaces}

The learning spaces group reviewed student use of existing spaces while collecting information on exemplary learning spaces in other institutions and making recommendations based on characteristics of the university's student body and its desired curriculum. They engaged students in their review of existing spaces by having them create photo diaries that illustrated space usage, the best and worst spaces, and reasons for their preferences. The group combined student feedback with selected bestpractice designs and launched pilot projects to renovate five existing spaces. Student responses to these spaces were extremely positive, and students began to use the spaces in numbers not seen previously on the campus. 5

The first four pilot projects entailed renovations of informal student learning spaces, where students meet, relax, and conduct a mix of schoolwork and other activities. A series of post-occupancy evaluations (POEs) identified both the qualities and characteristics that seemed to make the spaces successful as well as many specifics about student use of the spaces, such as peak times and popular technologies. The POEs also exposed some problems that the group addressed in future planning, such as a need for spaces for larger groups, monopolization of Internet kiosks, and excessive noise.

\footnotetext{
${ }^{5}$ See "future spaces now: planting the seeds of change," University of Technology Sydney. http://www.uts.edu.au/sites/default/files/FutureSpaces2ndEditionWeb\%5B1\%5D.pdf.
} 


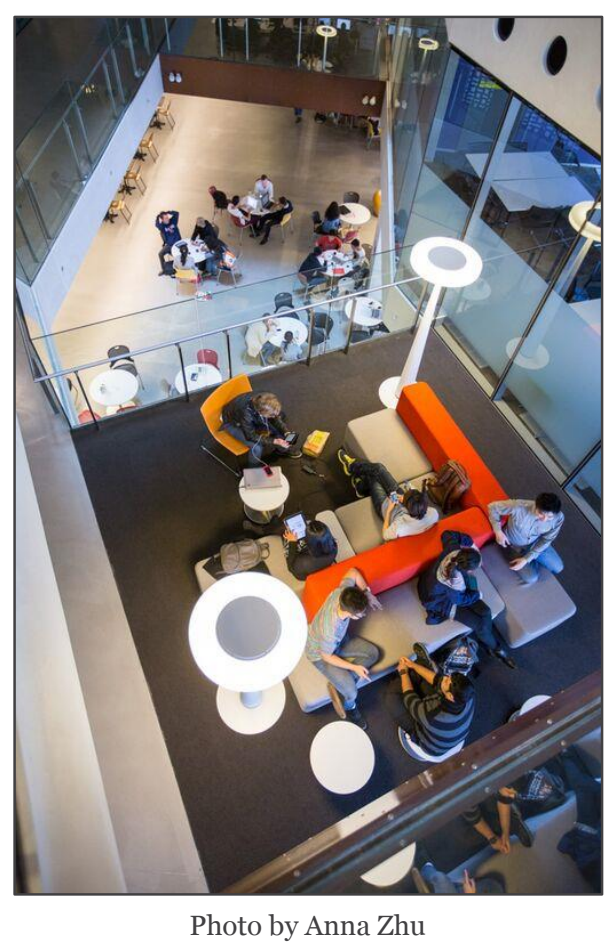

The fifth project entailed redesign of a formal learning space and endeavored specifically to create instructional space for group work rather than large lectures. Additionally, the space had to support the distribution of shared visuals to all groups and the use of sophisticated computer applications. In other words, the new learning environment was designed to support just the sort of changes the curriculum group wished to promote, that is, a reduction in lecturing and a shift toward active and more varied learning activities. As with the previous projects, this pilot was seen as an opportunity to experiment on a limited basis before making major investments in entirely new structures.

It was anticipated, and indeed it turned out to be the case, that the five pilots would create the conditions to enable UTS to successfully move forward with designing new structures. This was because the pilots provided an opportunity to test new space configurations and technology enhancements and to develop experience in design concepts, design processes, and team work. The POEs demonstrated to the leadership the value of investments in these spaces and convinced them that it was worth the large investments required to scale up the renovations. The pilots also provided an opportunity to build an understanding of the multitude of supports that were necessary to make new spaces work. This in turn led to the inclusion on a cross-functional committee of library, IT, cleaning, security, facilities management, and AV personnel to manage the spaces. 


\section{Components of the Learning2014 Initiative}

Learning2014 and learning.futures constitute sequential stages of an ongoing effort to transform the physical campus, the curriculum and corresponding approach to learning, and the university itself. Learning2014 owes its name to a desired shift from instructorcentered teaching to student-centered learning and a 2014 target date of occupying new, purpose-built learning spaces. Since the beginning of 2015, the initiative has been called learning.futures, but it still includes Learning2014 practices and continues work on its objectives.

Learning2014 started with the investigations and pilots of the four working groupspilots that allowed for experimentation in formal and informal learning spaces and approaches - and then shifted its focus to a large-scale, $\$ 1.2$ billion construction initiative along with major efforts to design curriculum and enhance the student experience. Key elements of these initiatives included the design and construction of seven new buildings, major changes in learning activities and assessments, and transformation of the way incoming students are oriented to the university and supported over their threeor four-year programs.

Learning2014 comprised a wide range of activities and projects. Some of the most significant of these were as follows.

\section{Construction of new buildings for engineering, business and science}

While the construction program included residential and other auxiliary spaces, the construction of new learning spaces was of particular importance to the academic objectives of Learning2014. Three of the most prominent academic buildings are the Dr. Chau Chak Wing Building, the Faculty of Engineering and IT Building and the building for the Faculty of Science and Graduate School of Health. ${ }^{6}$ From the outside, these buildings project vibrancy and currency, perhaps none more than the Wing Building. It is the first in Australia by Frank Gehry, the architect known for designing the Guggenheim Museum, Bilbao, and the Experience Music Project (Seattle).

\footnotetext{
${ }^{6}$ More information about these buildings and images are available at http://www.uts.edu.au/partners-andcommunity/initiatives/city-campus-master-plan/completed-projects/dr-chau-chak-wing, http://www.uts.edu.au/partnersand-community/initiatives/city-campus-master-plan/completed-projects/faculty-engineering, and http://www.uts.edu.au/partners-and-community/initiatives/city-campus-master-plan/completed-projects/science-andgraduate.
} 


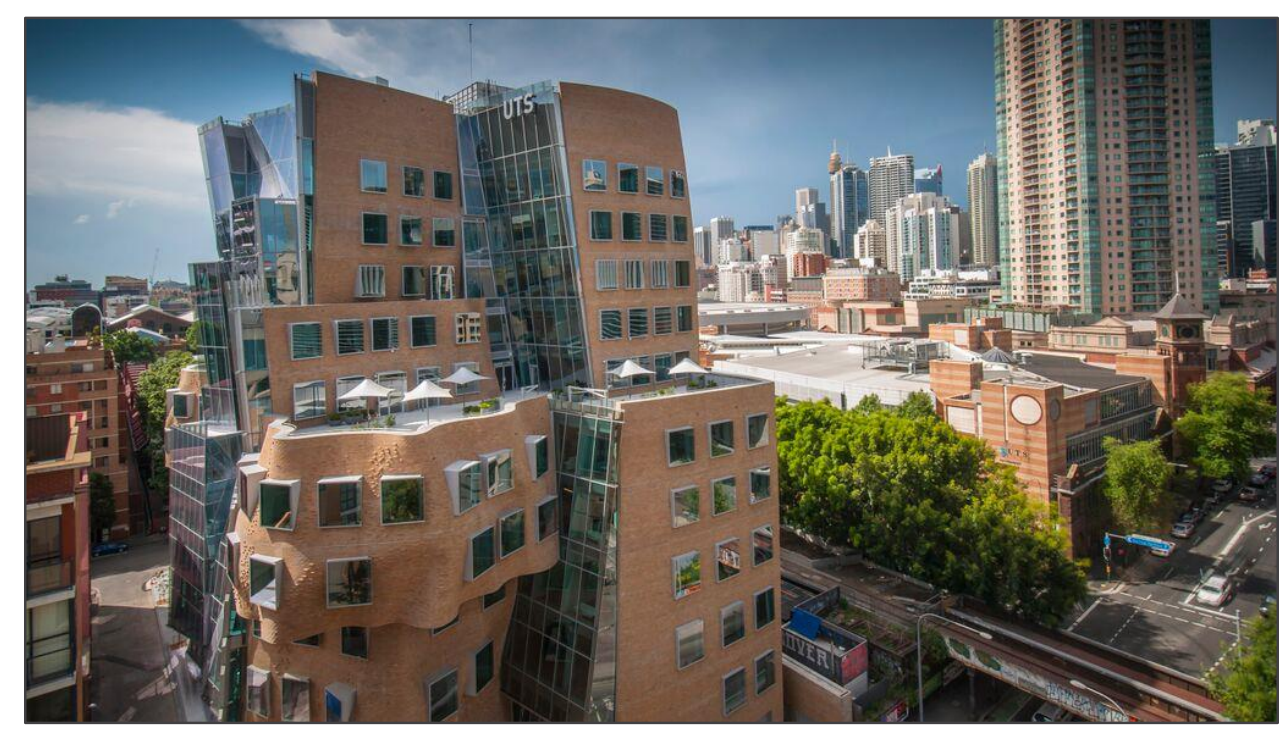

Photo by Andrew Worssam

On the inside, all new buildings are purpose built around the UTS Model of Learning in order to enable successful implementation of the new curriculum and the classroom practices associated with it. Features include banked spaces composed of broad "flat floors" that accommodate small groups; pods that enable technology-assisted group work; writable walls and flexible furnishings; and presenter's desks with an array of AV technology. As furnishings and dividers are movable, spaces can be set and reset to support whole-group or small-group discussions, presentations and seminars, project work, or combinations of lecture, presentation and group work, all with available technological supports. 7

\section{Development or transformation of courses based on the UTS Model of Learning}

The initiative to transform legacy teaching approaches into a new set of practices to better support student learning started on the heels of the construction program, and the two initiatives have since proceeded in tandem. Dated agreements were made with faculties to convert courses, and individual members of each faculty received informational, financial, and personnel resources to effect these conversions. Leaders gave presentations, spoke at conferences, and facilitated workshops throughout the year to describe the initiative and encourage the participation of members of the academic staff. In addition, staff who had already transformed their subjects shared their

\footnotetext{
${ }^{7}$ See "future spaces now: planting the seeds of change," University of Technology Sydney. http://www.uts.edu.au/sites/default/files/FutureSpaces2ndEditionWeb\%5B1\%5D.pdf.
} 
experiences with peers and encouraged others to design subjects in ways that fostered greater student engagement and active learning.

Staff came together to create the Flipped Learning Action Group (FLAG), which focuses on reviewing and applying research on the learning process and trying best practices to improve student learning outcomes. This effort was facilitated by the Institute for Interactive Media and Learning (IML), a faculty development unit that provides a range of services, including support for subject transformations. They do this in part by helping staff to redesign the curriculum, and use the best combination of online and face-to-face approaches to support students' learning. This may include the use of digital technologies to curate and deliver content and facilitate learning asynchronously, along with the use of new technologies to support interaction and collaboration during face-toface contact time. IML hosts workshops to introduce staff to methods and technologies for improving learning, and helps them implement these in term time when they are working with students. They also facilitate a large First Year Experience learning community, which provides another way for academic and professional staff to share effective practices across the university.

Staff have taken a variety of approaches to improve student learning in their subjects, but they have been careful to review the literature on best practices and discuss their methods with colleagues and instructional designers. Some staff have introduced flipped learning so that students review the content outside of face-to-face instructional time through online videos or readings and then engage in small group discussions and problem solving activities in the classroom. Other staff have integrated social media with more traditional instructional media, sharing content and assignments with students through multiple channels.

\section{Use of best available technology in support of learning}

As a technology focused university, UTS is committed to leveraging state-of-the-art technologies to optimize the learning environment and support research and learning. UTS students must develop familiarity with basic tools as well as expertise with the specialized tools associated with their areas of study. They should be exposed to a wide array of the newest tools and must achieve proficiency with the best of them in anticipation of using them in the workplace. Technology is not only something that is studied and learned; it also has an assistive role as one of a number of components in an overall learning system. Thus, technology plays multiple roles and is used in different ways throughout the institution.

Staff are encouraged and supported in using new technologies. This places burdens on IT organizations while also making IT essential to the success of UTS. The burdens come in 
the form of scheduling and load challenges, particularly around the beginning of term when demand for IT support may outstrip the capacity of the team.

\section{Graduate attributes and student transitions}

Because UTS seeks to become one of the leading technology universities in the world by 2018, it committed resources to developing clear statements, specific to each program (COURSE), of the desired characteristics, abilities and achievements of its graduates. This work was gradually launched in the early 2000s, more fully developed in undergraduate courses from 2007, and then made the focus of a major project between 2012 and 2015. Its completion is a major goal of learning.futures. In general, these attributes require that a graduate:

» Is equipped for ongoing learning in the pursuit of personal development and excellence in professional practice;

» Operates effectively with the body of knowledge that underpins professional practice;

»Is committed to the actions and responsibilities required of a professional and a citizen.

These attributes orient learning toward effective application of knowledge as well as the development of competence as an adult, a professional, and a citizen who is reflective, globally engaged, grounded in disciplinary research and practice, and equipped for lifelong learning. ${ }^{8}$ Specific attributes within the general framework might include, for example, "cross-cultural understanding and communication skills" or "critical and independent thinking and capacity for judgment."9

Closely related to the growing importance and utilization of graduate attributes is an overall shift in the university's relationship with individual students and expectations of them. This is clear from students' early interactions with the university and the ways they are integrated into the UTS community. Moving away from its former turnkey orientation, UTS now begins outreach to students before they arrive on campus with information about the differentiating characteristics of the UTS approach and the university's model of learning. For example, admitted students are informed about UTS

${ }^{8}$ For more information on the UTS Graduate Attributes Project: http://www.uts.edu.au/research-and-teaching/teachingand-learning/initiatives-and-support/graduate-attributes-project.

${ }^{9}$ See "2011 UTS Graduate Profile Framework," University of Technology Sydney. http://www.iml.uts.edu.au/pdfs/GraduateProfileFramework2011.pdf. 
learning environments with text and video explanations. ${ }^{10}$ Additionally, students are encouraged to think of themselves as professionals from their first days at university.

\section{Features of the Learning2014 Initiative as a Process}

\section{Top-down vision with bottom-up conditions for implementation}

Several UTS leaders played active roles in conceiving Learning2014 and launching it. They developed and disseminated a vision from the top of the organization, while creating the conditions and providing the wherewithal for implementation by UTS academic and support staff and administrators at every level. Leaders have been frank in their ownership of the vision, and while they did not use a university-wide consensus model, they did work together through many contentious issues to achieve the alignment that such an ambitious plan required.

Learning and curricular matters fall into the bailiwick of Professor Shirley Alexander, Deputy Vice Chancellor (Education and Students). All working groups associated with Learning2014 were located within her organization. Professor Alexander's contribution to the vision has been a leading one. Named number 29 of The Australian's "Higher Education Top 50," she is recognized for her commitment to the physical campus rather than MOOCs at a time when online learning is drawing interest as a means of cost containment and improved learning outcomes. ${ }^{11}$

Patrick Woods, Deputy Vice Chancellor (Resources), has responsibility for both the budget and the master plan for the university. ${ }^{12}$ His commitment to large-scale improvement of the facilities and to developing the financial resources to pay for several major projects were crucial in envisioning the Learning2014 initiative, not just on the building side but as an integrated whole that combines the transformation of facilities and pedagogy into improved learning environments.

\footnotetext{
${ }^{10}$ For more information on some of the university's new learning environments: http://www.uts.edu.au/currentstudents/new-learning-environments/how-you'll-learn.

${ }^{11}$ See "Higher Education Top 50, Part Two," The Australian (2014). http://www.theaustralian.com.au/news/highereducation-top-50-most-influential-people-2014-part-two/story-fnolgd60-1227153013039.

${ }^{12}$ For more information on the university's City Campus master plan: http://www.uts.edu.au/partners-andcommunity/initiatives/city-campus-master-plan/overview.
} 
Other principals include the former president, Ross Milbourne, who provided early sponsorship and the current president, Atilla Brungs, who has continued to advocate for the changes to the campus and the full implementation of learning.futures. Furthermore, other members of the Senior Executive have contributed both their expertisesometimes including opposing perspectives-and the resources of their respective organizations. ${ }^{13}$

\section{Information sharing, support for innovation and rewards}

In order to garner staff support and successfully launch Learning2014, the Deputy Vice Chancellor (Education and Students) and her team initiated a series of presentations and information sessions to share the vision, logic behind it, and details of the initiative. Venues have included annual faculty board meetings, the Teaching and Learning conferences, sessional staff conferences, senior management group meetings, and the university council. In ongoing workshops, staff first discussed proposed changes and the re-imagination of existing courses and then began to share experiences, concerns, questions and successes. In particular, the four-day Learning2014 Festival, tied to the opening of the new engineering building, is said to have been particularly effective in spreading awareness and stimulating takeoff of the initiative. At this event, staff who had already tried new learning approaches shared their results in small groups sitting in pods in one of the renovated spaces, simultaneously explaining and enacting their new approaches.

As part of the outreach and recognition component of Learning2014, four staff were named Future Learning Fellows; they have pioneered the transformation of subjects and shared results and resources with their peers. In addition, the Learning2014 initiative included the intentional creation of "communities of practice" to provide novice and experienced staff participants in the initiative with practical and moral support through a process of significant and ongoing change.

Staff told us that information they received about improvements in student learning resulting from course and subject redesign has been most influential in gaining their interest and participation. While metrics are not yet available, staff have shared anecdotal information about increased student engagement with the material, peers and instructors. Staff have also used new media to engage students and staff colleagues - an example is the blog hosted by Professor Jeff Browitt: "Testing Flipped Learning." ${ }^{14}$ This

\footnotetext{
${ }^{13}$ For more information on the university's Senior Executive: http://www.uts.edu.au/about/university/senior-executive.

${ }^{14}$ See "Testing 'Flipped Learning'." https://testingflippedlearning2013.wordpress.com/.
} 
blog enacts, critiques, and serves as a vehicle for sharing with colleagues and other interested parties.

Some staff have reported better student understanding of concepts in redesigned presentations, and students themselves have given positive feedback about the pedagogical changes. All Student Satisfaction Survey items related to learning spaces are now ranked by students as high on importance and high on performance. Results of a national University Experience Survey show statistically significantly higher UTS student perception of "learner engagement" than at other Australian universities (UTS students indicated 68 percent satisfaction vs. Australia 61 percent across Australia). The learner engagement factor includes items such as "I worked with other students as part of my study" and "I participated in discussions online or face-to-face." 15

Small grants to staff have provided an incentive and a needed resource, enabling them to redesign subjects. These grants may be used for course materials or to "buy time" away from other commitments to spend on subject redesign. Additionally, each school has an associate dean who is responsible for teaching and learning. These associate deans meet monthly to discuss the best ways to help staff implement Learning2014.

\section{Research basis of content, pedagogy and learning activities}

Importantly, while the vision comes from leadership, its implementation depends on academic staff and is driven by research in each discipline combined with research on learning. While few staff come to their faculty positions with a background in educational theory, many have developed expertise in this area in order to learn from the best practices of other academics and to improve learning outcomes for their students.

Research influences the content of subjects and pedagogical approaches; it also orients many student activities. Staff incorporate current research in their fields into the tutorials, bringing students up-to-date content while also helping them connect to the activities of research and the important researchers in their fields. Staff also research a range of pedagogical approaches in their disciplines and in higher education more broadly so that they are using effective methods to engage students and enhance their learning.

${ }^{15}$ For in-depth results from recent University Experience Surveys: https://education.gov.au/university-experience-survey. 


\section{Attention to all aspects of creating, using and maintaining learning environments}

The Learning2014 initiative is unique among many efforts to transform teaching and learning because it looks at learning from multiple angles and focuses on learning above all else. The leaders of this initiative recognized that in order to achieve the broad and deep transformation they sought, they needed to look beyond the legacy teaching methods of the pre-digital age. While those methods are still valid, and while they are still in use where appropriate, they are not always best. Today there are numerous alternatives, made possible by innovations in technologies for creation, utilization and communication of information.

However, learning environments that make heavy use of digital technologies and other mechanical and electronic tools can only succeed when everything is in working order. Proactive installation of a robust, campus-wide wireless network was crucial to expanded use of learning and administrative technologies. High-quality support services have also been key, especially to staff participation. The Institute for Interactive Media and Learning (IML) has participated throughout the life of the initiative, supporting curriculum design, assessing graduate attributes, conducting teaching and learning assessments and supporting staff research into the effects of their innovations on learning. IML staff had input into the design of the spaces in advance of construction and have worked on understanding what the new technologies are and how they can be used in teaching.

Similarly, the classroom audio-visual group has provided support to academic staff in using technology in classrooms. When new buildings are opened or new spaces are made available, the audio-visual group sets up the space and prepares them for staff use, supporting staff when they first use the new spaces and responding as new needs arise. For each new building, a team of students is employed for the first two weeks of the semester to help staff in each subject and to collect information about what should be done differently in the future. For example, handy guides to the use of equipment were developed as soon as support staff recognized the need and found the time. The guides obviate the need for some services previously provided face to face and provide step-bystep information about the use of equipment, such as interactive whiteboards. ${ }^{16}$

\footnotetext{
${ }^{16}$ See "Interactive Whiteboards @ University of Technology Sydney." http://www.uts.edu.au/sites/default/files/IWB\%20UTS\%20Initial\%20Guide 0.pdf.
} 


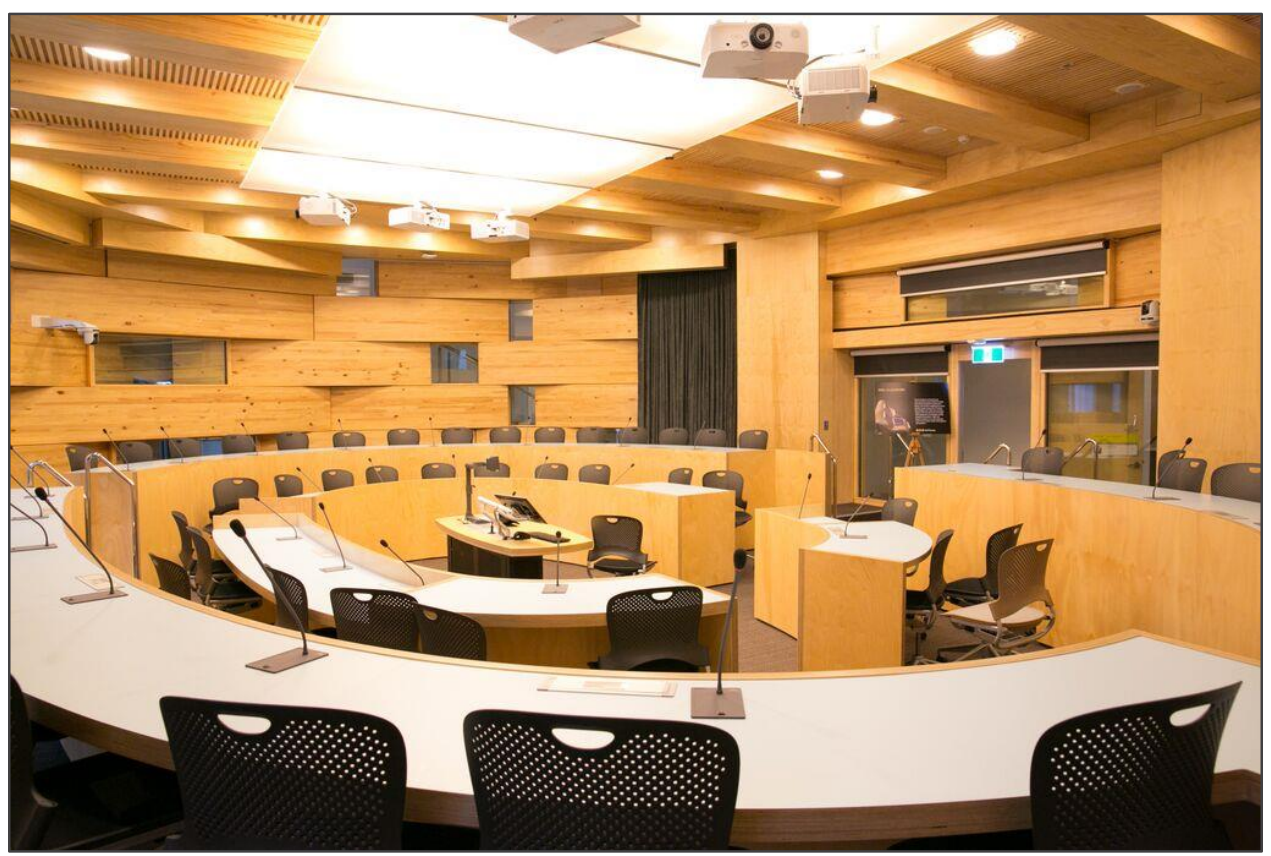

Photo by Andrew Worssam

Campus maintenance has also received careful attention from the director of facilities and from facilities support staff. These efforts have ranged from basic cleaning and the arrangement of furnishings to matters of safety and wellbeing. Attention has been paid to design, for example, by proposing the installation of more glass to enable students to see their surroundings and to make possible for guards to provide better security. In the area of planning, the delivery of custodial work had to be rescheduled from nights to days in order to ensure adequate cleaning during peak times. In sum, the new spaces require new or newly reorganized services to keep them in good order, sometimes entailing changes and costs that the university must absorb, above and beyond the initial costs of construction.

\section{Supporting change with carrots and sticks}

New learning spaces have been key to the Learning2014 initiative. UTS's new buildings provide no lecture halls and the classrooms were specifically designed to facilitate active learning and thereby foster the UTS vision. Some staff who had not re-designed their subjects, and were skeptical about the new approaches, were assigned these classrooms and forced to reflect on how their teaching fit with these spaces and the university's goals for student learning. Pressure on staff to think critically about how they are teaching has in some cases catalyzed efforts to teach in different ways. Upon seeing the new spaces and seeing how students use the technology in those spaces, staff have become eager to design subjects that could be taught in them. We also heard that students would soon be 
asked to evaluate their subjects by criteria that directly relate to implementation of the UTS Model of Learning; this is expected to encourage further compliance with Learning2014 and learning.futures changes.

The scale of the university's investment in renovation and new construction signals a long-term commitment to new approaches to learning. Staff cannot ignore the changes taking place around them; while not everyone is supportive, the excitement generated by the transformation of the campus has brought many additional staff on board. Furthermore, students seem very excited about the new spaces and the new ways in which subjects are presented. Demand for active-learning spaces is growing rapidly and the university is continuing to build more spaces and renovate existing ones.

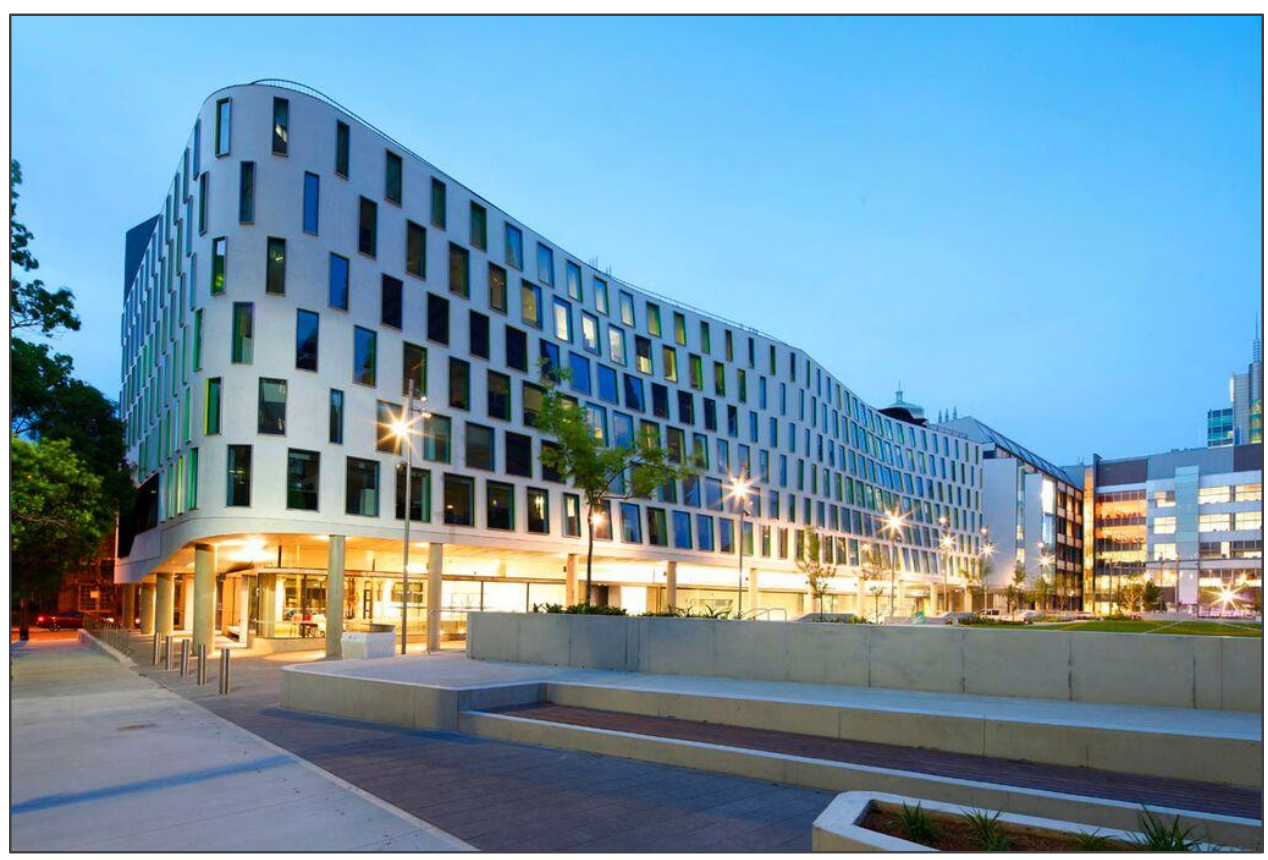

Photo by Richard Crookes Constructions

Among staff and students, there is an emerging consensus that these spaces are critical to the transformation of learning at UTS. The new buildings also allow for more crossdisciplinary activity and fit with goals to focus on practice-oriented education and industry-ready graduates.

UTS has initiated a system of peer review of the learning design of courses and subjects. In its learning.futures agreement, each faculty unit nominates the courses and subject that will be brought into compliance. Faculties also nominate staff to conduct peer reviews of courses and subjects from a different faculty from their own. Peer reviewers 
participate in collaborative professional development workshops and practice reviews before conducting compliance reviews. They use criteria related to intended learning outcomes, learning approaches, assessment approaches, and overall alignment of course or subject design with learning.futures objectives.

Annual learning and teaching awards and citations recognize outstanding contributions to student learning that are aligned with UTS learning priorities. The academic promotion process recognizes exemplary contributions to learning and assessment innovation, development of graduate attributes, leadership of course redesign and contributions to peer review, among other criteria. Academic workload policies are being redeveloped.

\section{Overall management of resources and projects}

Collaboration among senior leaders has been crucial, although it was not achieved without debate and continues to provoke discussion and friendly disagreement. Two members of the Senior Executive-the university's leadership team-have driven hard to carry the initiative forward. They are Shirley Alexander (Deputy Vice-Chancellor for Education and Students) and Patrick Woods (Deputy Vice-Chancellor and VicePresident for Resources), who have general responsibility for curriculum and learning and for facilities and resources, respectively. Longstanding backing from UTS's presidents combined with the collegial support of the entire Senior Executive have made the initiative possible, although it still would not have been possible without the tenacity and executive ability of the principals.

Tenacity and talent have been crucial not just at leadership levels but at all levels of the organization. Each member of the Senior Executive has a clear understanding of his or her responsibilities for making the university vision a reality. In addition, they are willing to take risks and experiment with new methods, which is key to making the innovations possible. Staff have been persuaded by the alignment and audacity of senior leaders and have seen a shift in the culture of the university.

The scale of the collaboration has enabled administrators to combine projects and share resources in some cases. Nowhere is this more evident than in the partnership of the vice president of resources and the deputy vice chancellor of education and students, who have worked closely together to develop a plan to design the new buildings on campus explicitly to achieve curricular transformation.

The vice president of resources, Patrick Woods, came to UTS with extensive high-level corporate experience in finance, technology and other industries. He has augmented UTS's tuition dollars with AUS\$50M from the federal government and an additional 
AUS \$20M grant from an individual philanthropist to fund more than AUS $\$ 1$ billion in construction and renovation costs. Growth in enrolments will support proper upkeep, necessary rework, and further construction projects.

Once the vice president of resources earmarks the funds, they must be carefully shepherded. One way this has been accomplished is through careful project management, both by Nigel Oliver, the director of the program management office, and by teams dedicated to project control for each component of the construction initiative. As with financial management, project management on a large-scale, and especially with industrial contractors and builders, requires skill sets unusual and in some cases almost antithetical to those typical of universities. Yet just these skills turned around an early project and allowed subsequent projects to proceed on acceptable budgets and timetables.

\section{Challenges}

Learning2014 has experienced challenges related to its magnitude but also to its cultural impact. The push to improve student outcomes and increase the university's focus on learning has created tension for some members of academic staff related to their promotion prospects.

The promotion process is the major source of staff rewards, whether from probationary to regular status or to achieve further advancement. Many criteria are considered in this process, including teaching and educational development, research and scholarship, and engagement and academic management. While there are exceptions for individuals with research-only or education-focused appointments, teaching and research are equally weighted in the promotion process for almost all staff. This equal weighting notwithstanding, some staff worry that time spent on improving subjects may have the effect of reducing time spent on research, thereby reducing research productivity and adversely affecting their promotion.

Aside from questions of time allocated to teaching vs. research, some staff remain unconvinced by learning.futures, while others are open to the new model but may be slower to implement changes to their own practices. There is some concern over exactly what is signaled by the lack of lecture theatres in new buildings. Is it, in the words of one person, "throwing the baby out with the bath water"? Or is it the case, as another put it, that "commitment to professional practice-making sure students develop workplace skills-is something you cannot do in a lecture and that drives some of the people to change their approach"? Another individual tried to put the question of instruction into perspective, explaining that it was not the case that staff "have to stop [lecturing] or else. 
People claimed they were being made to not lecture or that it was just administrative interference, others said no, you just have to see that students need to be taught by the best means, not just by lecture."

The percentage of staff who have taken up the new approaches varies by school and discipline. In some areas, such as business and engineering, a majority of the academic staff are becoming engaged in learning.futures and exploring more innovative and practice-oriented classroom strategies. However, in other fields such as journalism, some staff are less convinced that the new methods of teaching are worth the time required to redesign a subject. Staff who have already re-designed their subjects or are teaching in transformed learning spaces are more positive about the new models. Even skeptical staff find it hard to argue against the project's core mission of improving student learning. Indeed, part of the power of Learning2014 is that no one has floated a competing vision with similar force or conviction. But if the changes are not done well, there is the fear that student learning will suffer.

Fortunately, students have responded to the changes in visibly positive ways. For one thing, significantly more students now spend time on the campus, lingering after class to use campus spaces to study, socialize, and engage in university activities. Additionally, students we met endorsed learning.futures and expressed pride in their university, even while acknowledging that the new model of learning requires more work than straight lectures. Active learning requires that students absorb content beforehand and then engage in activities throughout the instructional period itself. Some students have complained that this demands too much time and effort on their part, and some academic staff mentioned that students may struggle and even fail if they do not understand or have the maturity to assume a heightened responsibility for their own learning. However, students and staff have also noted that the new methods greatly improve student learning, and many feel that it is worth the additional effort. The university is still exploring ways to communicate the changes to students and help them understand and prepare themselves for the requirements and benefits of these new approaches. ${ }^{17}$

Another set of challenges has revolved around the speed and duration of the initiative. On the one hand, some support staff have complained that they have not had enough time to prepare. For example, the interval during which technology can be set up and made operational has not always been long enough to allow the $\mathrm{A} / \mathrm{V}$ and classroom support technicians enough time to ensure adequate support. On the flip side, others have been frustrated by waiting periods for new and renovated classroom spaces. There

${ }^{17}$ An example is the video for incoming students, mentioned above. 
were not enough spaces available, and some staff did not want to bother making the changes if they did not have access to one of the new learning spaces.

More support staff would have made the opening of new buildings and the transformation of subjects much smoother. The number of spaces AVS supports doubled but the staff did not. They have coped with this by shuffling around staff assignments, doing some remote management of facilities, and bringing on more student workers, especially at the beginning of each term. By charging some faculties for the services they provide, they are able to pay overtime for regular personnel or hire part-timers to fill gaps, but they find that they are usually working to capacity. Support staff also felt rushed to roll out their services when the first new building was opened. It would have been easier if they had more time and staff to solve the problems.

There is worry that "change fatigue" may set in and challenge momentum. Some staff have reported that they feel pushed to the limit and wish that supports and processes were fully implemented to make the transitions smooth. Other staff have mentioned that they feel they need to pick and choose the changes that they want to make, at least in the short term.

Despite the challenges, the changes are seen as overwhelmingly positive. Many of the challenges were predicted ahead of time, and forethought and adept responses have enabled the project to continue moving forward quickly and with impressive preliminary results.

\section{Evidence of Impact}

Although it is still early days for Learning2014 and learning.futures, there are already indications of success. For example, post-occupancy evaluations of redesigned spaces indicate that students frequently use the spaces and rate them highly. They also suggest that students are more actively engaging with their peers and with subject content. Staff report anecdotally that student understanding and engagement have grown in the redesigned subjects, and students' end of course evaluations also rate the new subjects more highly than the previous versions. Student reactions to our interview questions were also positive in regard to redesigned subject formats and new learning spaces. 
Results from the Student Satisfaction Survey and the University Experience Survey, discussed above, provide early positive metrics. ${ }^{18}$

Increased demand is another indicator of success. Student and staff demand for new and upgraded facilities has grown rapidly. Furthermore, we were told that, "Within the faculty, people are now starting to use the language of Learning2014 and use the Learning2014 strategy to make decisions about courses and subjects." Relatedly, UTS is attracting new staff who are innovating and reporting positive student feedback and experiences. Students now have a much larger presence on campus than they did a few years ago and they speak highly of the spaces available to them.

It is too early to see one highly sought desired indicator of impact: increased demand for UTS graduates in industry. However, students appear to value the strong ties to industry and the relevance of what they are learning to their future careers. In at least some areas, such as architecture, the UTS degree is becoming known as characteristically "high tech" and thus desirable in many quarters.

U.S. News and World Report ranks UTS number 21 in its list of Best Global Universities in Australia/New Zealand, and the Times Higher Education World University Rankings gives UTS high scores in International Outlook. ${ }^{19}$

\section{Next Steps}

The initial work of master planning, development of the new model of learning, and the first phase of construction and curricular transformation is complete. What remains is reconsideration of the UTS Model of Learning, now several years old, review of the graduate profile framework, completion of further planned construction, and institutionwide conversion of subjects and courses with accompanying graduate attributes.

Construction projects will include demolition of the building housing the first renovated space to make way for a new learning commons that includes a $24 \times 7$ library with a stateof-the-art book retrieval system. The campus will be further unified by transformation of

\footnotetext{
${ }^{18}$ For more information on the Student Satisfaction Survey and the University Experience Survey, respectively: http://www.uts.edu.au/current-students/campus-life/communication-uts/your-feedback-counts/student-feedback-survey https://education.gov.au/university-experience-survey.

${ }^{19}$ For the U.S. News and World Report profile, see: http://www.usnews.com/education/best-global-universities/universityof-technology-sydney-505153. For the Times Higher Education profile, see: https://www.timeshighereducation.co.uk/world-university-rankings/university-of-technology-sydney?ranking-dataset=1083. The "International Outlook" category here examines diversity on campus and the degree to which academics collaborate with colleagues in other countries on research projects.
} 
an old rail spur into a walkway connecting Darling Harbor, the Powerhouse Museum, and Central Station via the heart of the UTS campus.

On the curricular side, faculties have individual agreements with the university to achieve timely conversion of subjects. Staff will receive resources to effect these conversions but will also be subject to a university-wide system of peer review to ensure compliance. Additionally, changes in the ways students provide feedback may contribute to staff thinking on new practices.

Course conversion will be accompanied by additional work on the assessment of student learning and the connection between assessment and graduate attributes that relate to skills in a wide range of areas, including new media literacies, data familiarity, transdisciplinarity, and numeracy. Transdisciplinarity in particular is relevant to preparation for students entering industry in rapidly changing fields, where the future is uncertain and innovation regularly occurs by crossing disciplinary boundaries. Accordingly, learning.futures has seen the launch of new transdisciplinary courses, beginning with the Bachelor of Creative Intelligence and Innovation and the Master of Data Science and Innovation. Other new offerings are in development. In these new courses, students are to work with complex problems, using diverse, creative perspectives drawn from different disciplines and stakeholders, reframing problems through this approach to generate, test, and bring new ideas to fruition for the common good.

As learning.futures moves forward, the strategy will focus on the following elements:

» The continuation of Learning2014 practices, such as flipped learning

» Review of the UTS Model of Learning and Graduate Profile Framework

» Strategies to enhance the employment outcomes of students

» Opportunities for all students to undertake an internship or similar experience

\section{Success Factors}

Several features of the Learning2014 initiative and its implementation stand out as key to its success at UTS.

1. The leadership had a vibrant presence and provided the university with a clear vision. Leadership communicated the vision clearly and frequently to staff and other key stakeholders around the university. Everyone at UTS knew what Learning2014 was, how it was being carried out, and how they could become involved. In addition, the leadership committed substantial resources to this initiative and made sure adequate support was readily available. 
2. Staff were provided support so they could become involved in selecting and implementing new methods of learning and designing the spaces in which they would teach. The initiative invited participation throughout the university community and elicited contributions from a wide variety of stakeholders. There were multiple opportunities for staff to share innovative practice and learn from others.

3. Research was given a central role in the initiative in traditional ways-including support for a strong research basis within the disciplines-as well as novel ways-such as fresh attention to theory and research on student learning as the foundation of the new pedagogy and the inspiration for innovative classroom approaches.

4. Support services enabled change on a large scale and ensured that staff were able to do their part.

5. Evidence of the impacts of new spaces and new methods motivated additional staff to engage in the project and encouraged further renovations of learning spaces.

6. Technology was understood to be essential and every effort was made to implement the best tools for each need.

7. Student learning has remained central throughout. The four-fold focus on the students, curriculum, space, and technology has been key to the success of this initiative: how students learn, what they learn, where they learn, what they will do with what they learn, and what tools facilitate their learning.

\section{Conclusion}

Over the past eight years, UTS has undergone a remarkable transition, from a tired campus that housed an unsung technical institute to a major presence in Australia's largest city where learning and research draw the attention of students, the higher education community, industry, and the public.

Students have a strong presence and are engaged in learning throughout the campus. Learning.futures now continues the work of Learning2014, drawing on and extending the work that has already begun. New renovations are under way and staff continue the work of implementing transformed courses. The connection between UTS and its Sydney neighbors in the arts precinct and central business district continue to grow through campus visits, student co-ops and internships, and the placement of graduates in a wide range of coveted technology positions.

UTS has shown that it is possible to change the way learning takes place on a large scale and with positive results. The integration of the top-down vision with conditions for bottom-up implementation has effected achievement of the leadership's broad and important goals through outstanding performance at all staff levels. There was a vision of UTS: expanded, renewed, and preeminent in its field. And there was a vision of its 
students: professional from day one and, upon graduation, talented, educated, technologically advanced, and competitive in the marketplace. UTS's unique combination of campus master plan and pedagogical innovation has enabled its remarkable progress to this point and will energize its continued efforts to improve learning and learning environments, foster creativity and innovation, build community and global connections, and utilize research on content and pedagogy in a real-world place that is purpose built for its visionary approach. 


\section{Appendix}

We conducted interviews with the following UTS administrators, academic and support staff, and undergraduate students on April 27 and 28, 2015:

» Shirley Alexander, Deputy Vice-Chancellor (Education and Students)

» Jeff Browitt, Senior Lecturer, International Studies Program

» Melissa Edwards, Senior Lecturer, Management Discipline Group

» Kathy Grattan, AVS Client Services Manager, Audio Visual Services

» Anne Gardner, Senior Lecturer, School of Civil and Environmental Engineering

» Tanja Golja, Senior Lecturer, Institute for Interactive Media and Learning

» Peter Kandlbinder, Senior Lecturer, Institute for Interactive Media and Learning

» Jo McKenzie, Director, Institute for Interactive Media and Learning

» Marilyn Harris, Executive Officer, Deputy Vice-Chancellor (Teaching, Learning \& Equity)

» David O’Connor, Manager, Web and Application Services

» Nigel Oliver, Director Program Management Office

» Jenny Pizzica, Lecturer, Institute for Interactive Media and Learning

» Jenna Price, Senior Lecturer, Journalism Program

» Glen Rabbitt, Director, Facilities Management Operations

» Patrick Woods, Deputy Vice-Chancellor and Vice-President (Resources)

» Undergraduate Students (Anonymous) 